\title{
Ecological Effects of Shoreline Armoring on Intertidal Habitats of a Puget Sound Urban Estuary
}

\author{
Sarah A. Morley • Jason D. Toft • Karrie M. Hanson
}

Received: 9 August 2011 /Revised: 16 January 2012 / Accepted: 20 January 2012 /Published online: 14 February 2012

(C) The Author(s) 2012. This article is published with open access at Springerlink.com

\begin{abstract}
Shoreline armoring is extensive in urban areas worldwide, but the ecological consequences are poorly documented. We mapped shoreline armoring along the Duwamish River estuary (Washington State, USA) and evaluated differences in temperature, invertebrates, and juvenile salmon (Oncorhynchus spp.) diet between armored and unarmored intertidal habitats. Mean substrate temperatures were significantly warmer at armored sites, but water temperature similar to unarmored habitats. Epibenthic invertebrate densities were over tenfold greater on unarmored shorelines and taxa richness double that of armored locations. Taxa richness of neuston invertebrates was also higher at unarmored sites, but abundance similar. We did not detect differences in Chinook (O. tshawytscha) diet, but observed a higher proportion of benthic prey for chum $(O$. keta) from unarmored sites. Given that over $66 \%$ of the Duwamish shoreline is armored - similar to much of south and central Puget Sound - our results underscore the need for further ecological study to address the impacts of estuary armoring.
\end{abstract}

Keywords Shoreline armoring · Upper intertidal · Urban estuary · Puget Sound · Duwamish River · Juvenile salmon . Invertebrates · Temperature

S. A. Morley $(\bowtie) \cdot K$. M. Hanson

Northwest Fisheries Science Center, NOAA Fisheries, 2725 Montlake Blvd. E,

Seattle, WA 98112, USA

e-mail: sarah.morley@noaa.gov

J. D. Toft

School of Aquatic and Fishery Sciences,

University of Washington,

Box 355020, Seattle, WA 98195, USA

\section{Introduction}

As human populations continue their exponential growth in cities, over half of the world's population now resides in urban areas (UNPF 2007). Nowhere is urban development more concentrated than around the world's estuaries, which as major transportation corridors and fertile agricultural areas have typically served as the epicenters of human settlements (Lotze et al. 2006; Peterson and Lowe 2009). Among the many ways in which human activities have degraded estuarine habitats, shoreline modification is among the most pervasive (Airoldi et al. 2005; Bulleri and Chapman 2010). Common practices such as shoreline armoring and associated removal of riparian vegetation decrease habitat complexity and reduce connectivity to terrestrial habitats (Peterson et al. 2000; Romanuk and Levings 2003).

As active areas of sediment and organic matter exchange between land and water, estuarine shorelines are physically complex and biologically rich (Lubbers et al. 1990; Ruiz et al. 1993). The extent to which shoreline armoring disrupts this land-water interface and alters habitat quality for intertidal and supratidal species is poorly understood (Rice 2006; Jackson et al. 2008). Yet increasing shoreline development pressure and predicted sea-level rise suggest that shoreline armoring will continue to spread globally (NRC 2006; Dugan et al. 2008). Greater study of the biological effects of shoreline armoring is needed to improve future shoreline management (Bilkovic and Roggero 2008) and provide context for regional restoration efforts such as the Puget Sound Nearshore Ecosystem Restoration Project (Shipman et al. 2010).

Puget Sound is the southern portion of the Salish Sea-a deep, well-mixed fjordal estuary that spans British Columbia and Washington State (Simenstad et al. 2011). As the Puget 
Sound area population has doubled to three and a half million people over the last three decades, shoreline development pressure has also intensified. Currently, a third of the total Puget Sound shoreline is armored, rising to over $60 \%$ in South-Central Puget Sound where most urban development is concentrated (Simenstad et al. 2011). At the industrial heart of the City of Seattle is the Duwamish River estuary-the gateway through which seven species of both hatchery-raised and naturally spawning anadromous salmonids (Oncorhynchus spp.) migrate between the forested headwaters of the Green River watershed and the saltwater of Elliott Bay (Blomberg et al. 1988; Ruggerone et al. 2006).

Considerable energy and funds have been dedicated to habitat restoration projects in the Duwamish River over the last quarter century (Simenstad et al. 2005). Much of this restoration work has focused on relatively small-scale shoreline improvement efforts that involve removing bank armoring, overwater structures, and seawalls that currently dominate the landscape; re-grading and softening banks; and re-vegetating shorelines (Cordell et al. 2011). As such, they are intended to increase land-water interaction, and thus improve habitat quality for fish - in particular, rearing habitat for juvenile salmonids. These are good goals, but they lack context. Relatively little is known about the biological consequences of shoreline armoring or to what extent intertidal communities differ between armored and unarmored habitats (Shipman et al. 2010; Sobocinski et al. 2010).

The objective of this study is to help address this data gap by examining differences in upper intertidal temperature, invertebrate assemblages, and juvenile salmonid diet in relation to shoreline armoring in the Duwamish River estuary. Specifically, we ask the following questions: (1) What is the extent and spatial distribution of shoreline modification across the estuary; (2) Does increased armoring and decreased shoreline vegetation alter intertidal temperatures; (3) How does composition of benthic and terrestrial invertebrates differ between armored and unarmored shorelines; and (4) Are these potential differences reflected in the diets of juvenile salmonids migrating through the estuary?

\section{Methods}

\section{Study Region and Design}

The Duwamish River is the tidally influenced portion of the $150-\mathrm{km}$ Green River $\left(1,274 \mathrm{~km}^{2}\right.$ area $)$ that begins in the City of Tukwila, flows northwest for $18 \mathrm{~km}$ through unincorporated portions of King County and the City of Seattle and empties into Puget Sound at Elliott Bay (Fig. 1). The saltwater wedge of Elliott Bay extends upstream as far as $16 \mathrm{~km}$; mean annual freshwater inflow is $48 \mathrm{cms}$, and tides

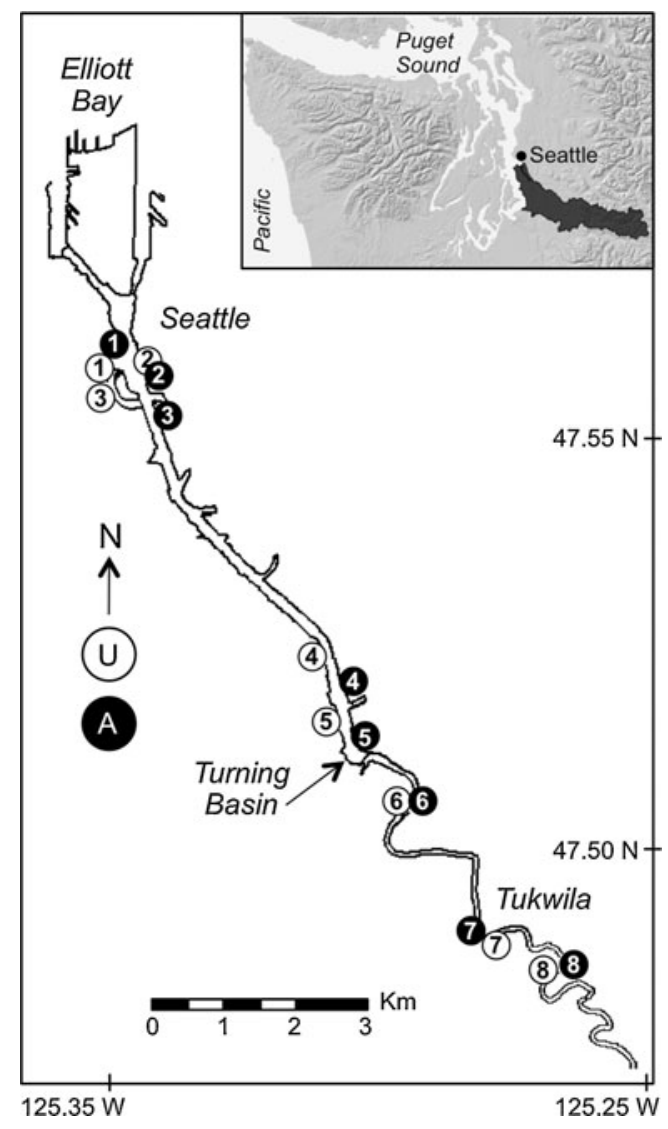

Fig. 1 Map of the Duwamish River and location of eight study reaches with spatially paired unarmored $(U)$ and armored $(A)$ sample sites. Inset map shows location of greater Green River watershed within the Puget Sound region of Washington State

are mixed semidiurnal with a mean tidal stage of $2.0 \mathrm{~m}$ above mean lower low water (MLLW). Over the last century, the lower Duwamish River has been reduced from $9.3 \mathrm{~km}$ of meandering estuary to $5.3 \mathrm{~km}$ of dredged, channelized, and armored shipping channel; over $97 \%$ of its mudflats and marshes have been filled, $70 \%$ of its drainage area diverted to other basins, and the lower river declared a federal Superfund site (Blomberg et al. 1988; Simenstad et al. 2005). Today, land use within the greater Green River watershed is primarily commercial forestry, mixed lowdensity residential, and agriculture - transitioning to highdensity residential and industrial in the Duwamish River sub-basin. Below the Turning Basin at river kilometer (rkm) 8.5, the US Army Corps of Engineers maintains the channel for shipping traffic and land use is almost exclusively heavy industry and Port of Seattle terminal facilities.

This study is composed of three parts: shoreline mapping, habitat characterization, and biological sampling. We conducted shoreline mapping to inventory shoreline modification across the entire Duwamish and selected eight study reaches with paired armored and unarmored sites for 
comparison of habitat and biota (Fig. 1). Armored sites represented typical Duwamish shoreline: banks and intertidal zone armored in riprap (unconsolidated boulders or pieces of concrete) with sparse riparian vegetation. Unarmored sites reflected the most "natural" habitats available in the Duwamish: low-gradient mud and sand beaches with a mix of native trees [such as red alder (Alnus rubra), black cottonwood (Populus trichocarpa), big leaf maple (Acer macrophyllum)], shrubs [willow (Salix spp.), Nootka rose (Rosa nutkana), snowberry (Symphoricarpos albus)], and emergent vegetation [bulrushes (Scirpus spp.), sedges (Carex spp.)] (Fig. 2). Study reaches spanned rkm 2-15; each study site was a minimum contiguous length of $70 \mathrm{~m}$ (mean $=470 \mathrm{~m}$ ) and located no further than $0.75 \mathrm{~km}$ from its pair. Shoreline mapping, physical habitat, and invertebrate sampling took place in 2003, with fish sampling added in 2004.

\section{Shoreline Mapping}

We mapped the Duwamish shoreline by foot and boat using a TSC1 Trimble GPS unit ( $<1 \mathrm{~m}$ accuracy) and inventoried shoreline armoring and distribution of riparian vegetation at the ordinary high water mark (OHWM), visually
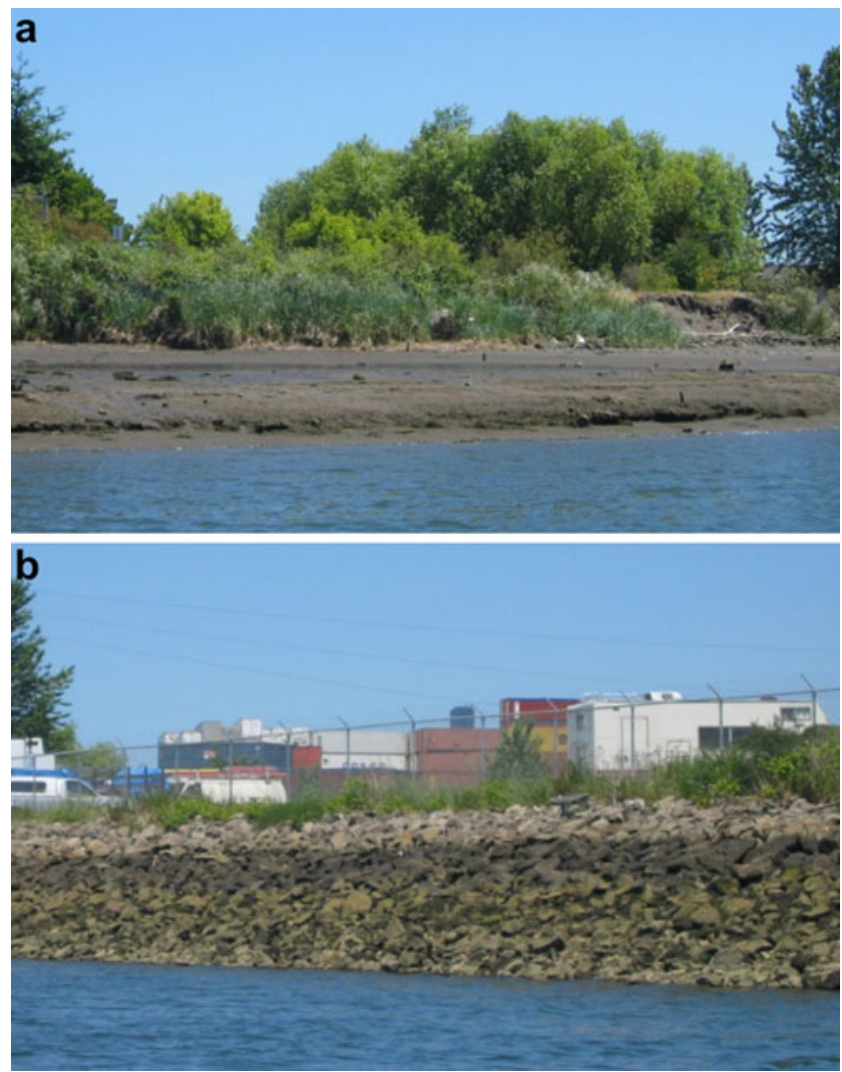

Fig. 2 Photos of a typical $\mathbf{a}$ unarmored and $\mathbf{b}$ armored study site at low tide distinguished by changes in soil and vegetation characteristics. Banks were classified into four major categories: bulkhead (retaining walls composed of concrete, steel, or wood), riprap, exposed mudflat, and vegetation-using $2 \mathrm{~m}$ as a minimum mapping length. Banks were classified as vegetated if any type of plant material grew immediately adjacent to the OHWM line. Thus, our estimates of total shoreline armoring are conservative. We checked our GPS field data against 2002 digital orthophotos (1-foot pixel resolution) and where discrepancies existed, visited sites again to verify appropriate classification. We then created a GIS shape file coded by shoreline type and calculated extent of bank armoring (bulkhead+riprap) and the spatial distribution of different patch lengths of shoreline vegetation in the upper and lower estuaries.

\section{Habitat Characterization}

At each of our 16 study sites, we recorded relative elevation (meters) and substrate type at $1-\mathrm{m}$ intervals along three transects extending $10 \mathrm{~m}$ perpendicular to the shoreline from the OHWM and from this, calculated mean bank slope (\%) and percent bank armoring. To characterize riparian condition, we digitally overlaid a randomly generated grid over 2002 orthophotos and calculated the proportion of total vegetative and tree cover within $10 \mathrm{~m}$ of the shoreline. To examine potential temperature $\left({ }^{\circ} \mathrm{C}\right)$ differences between paired sites due to shading from riparian vegetation, we installed temperature loggers within the upper intertidal at elevations $+2.0( \pm 0.25) \mathrm{m}$ MLLW-determined by timing and elevation of low tide events. Loggers were deployed from 2003-2004 and set to record at 15-min intervals. For the time period corresponding to our biological sampling (May-July), we used tide charts to determine the timing of logger submersion, and evaluated water (logger submerged) and substrate (logger exposed) temperature separately. One logger was lost to vandalism at study reach 2 , reducing our sample size to seven complete study pairs.

\section{Biological Sampling}

Biological sampling occurred in the upper intertidal zone during the lower of the daily high tides (2-3 m>MLLW) of late spring and early summer (mid-May to mid-July) when juvenile salmonids are migrating through the Duwamish (Ruggerone et al. 2006). To evaluate differences in invertebrate assemblages by shoreline type, we used a neuston net $(40 \times 20 \mathrm{~cm}$ frame size, $150-\mu \mathrm{m}$ mesh) to collect three $10-\mathrm{m}$ surface tows adjacent and parallel to the shoreline and an epibenthic pump (14.8 $\mathrm{cm}$ diameter, $150-\mu \mathrm{m}$ mesh size, 2min sample period) to suction invertebrates from the surface layer of the benthos from five randomly determined points along a transect parallel to shore (water depths $0.2-1.1 \mathrm{~m}$ ). 
Neuston samples were identified to order or family level and epibenthic samples to the lowest practical taxonomic level (ranging from species to order).

Fish were collected at five of the eight paired reaches (1, 3-6) where a net could feasibly be deployed and sampled on three occasions in May and June. Three non-overlapping seines were collected at each site using a floating beach seine $(2.0 \mathrm{~m}$ high at cod-end with $3 \mathrm{~cm}$ mesh joined to a $2 \times 2.4 \mathrm{~m}$ cod-end with $6 \mathrm{~mm}$ mesh) to sample a small area $(10 \times 10 \mathrm{~m}$ per seine $)$ adjacent to the shore. All fish were identified to species with up to 100 individuals from each species measured to the nearest $\mathrm{mm}$ (fork length for salmonids and total length for non-salmonids). Salmonids were classified as marked if their adipose fin was clipped or if they were implanted with a coded-wire tag (indicating hatchery origin).

To evaluate juvenile salmonid diet, we collected stomach contents from up to 15 individuals per site for Chinook (O. tshawytscha) and chum salmon (O. keta). Chinook were sampled using non-lethal gastric lavage, stomach contents preserved in formalin, and fish released after recovery. Due to their small size, chum fry were preserved in formalin for laboratory dissection. Prey items from both species were identified to the lowest practical taxonomic level, blotted dry, and weighed to the nearest $0.0001 \mathrm{~g}$. For a given prey item, we calculated the frequency of occurrence $(\% \mathrm{~F})$ across all samples, and the numeric $(\% \mathrm{~N})$ and weight $(\% \mathrm{~W})$ contribution of each prey taxa to a given fish. To rank the overall contribution of prey items to a sample population, we calculated the percentage that each prey item contributed to the index of relative importance (IRI) using the formula $\% \mathrm{IRI}=\% \mathrm{~F}(\% \mathrm{~N}+\% \mathrm{~W})$ (modified from Pinkas et al. (1971)).

\section{Statistical Analyses}

Shoreline spatial data were intended to be primarily descriptive and were graphically analyzed as described above. Similarly, because modified and natural sites were intentionally selected to differ in physical habitat features such as bank armoring, we present the habitat characterization data simply to illustrate the extent of morphological and riparian differences between paired sites. As beach seining is less effective at capturing fish at rocky and steep shores typical of our armored sites (Rozas and Minello 1997), we report the frequency of occurrence and relative abundance of different species across our study sites, but confine formal statistical analyses to diet data. Due to uneven catch rates across all study sites, we used a two-sample design for statistical testing of fish diet data (restricting analyses to those reaches where a species was present at both sites), but a paired design for all other datasets.
We tested for differences in temperature and invertebrate taxa richness and abundance with two-tailed $t$ tests and used simple linear regression to examine the relationships between pair-wise differences in temperature and invertebrate metrics to reach location and habitat features (\% armoring, slope, vegetative, and tree cover). To examine differences in invertebrate and fish diet assemblage structure relative to shoreline armoring, we used a suite of complementary multivariate techniques available in the statistical software packages PRIMER (version 6.1.13, Clarke and Gorley 2006) and PERMANOVA (version 1.0.3, Anderson et al. 2008). We square-root-transformed our data (densities for invertebrates, relative abundance for fish diet), created triangular resemblance matrices of pair-wise similarities between all sites using the Bray-Curtis distance, and tested for differences between armored and unarmored sites using PERMANOVA - a non-parametric analog to analysis of variance that uses permutation methods to test for compositional differences among groups of sites based on resemblance measures (Anderson et al. 2008). We employed a one-way randomized block design in PERMANOVA with shoreline type (armored or unarmored) as a fixed factor and reach (18 ) as random for invertebrate data and a one-factor model without blocking to test for differences in fish diet by shoreline type. Where significant differences were detected between armored and unarmored sites, we used the SIMPER routine to decompose average Bray-Curtis dissimilarities between pairs of samples and determine which taxa contributed most to dissimilarities between groups.

\section{Results}

Shoreline Mapping

Over its entire $18-\mathrm{km}$ length, riparian vegetation is present along only $35 \%$ of the Duwamish - the majority occurring

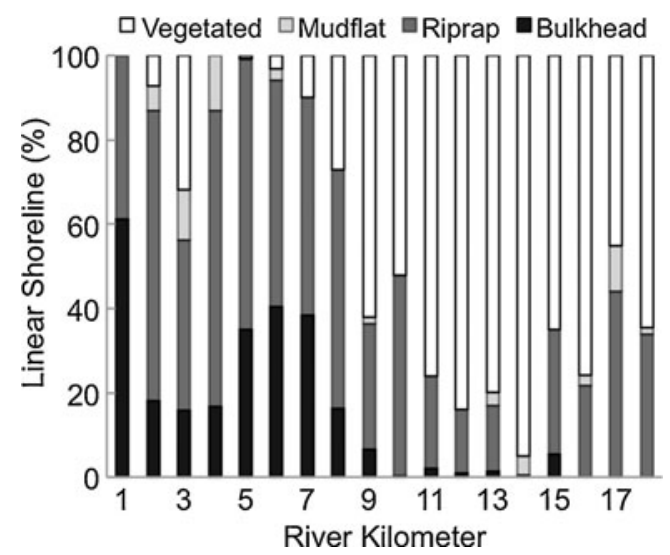

Fig. 3 Relative distribution of four major shoreline categories by river kilometer 
in the upper $10 \mathrm{~km}$ of the estuary (Fig. 3). Below the Turning Basin, less than $11 \%$ of the shoreline is vegetated, and the only stretches of continuously vegetated shoreline longer than $200 \mathrm{~m}$ occur at the Turning Basin and Kellogg Island (remnant mudflats built up by dredge spoils). Over $66 \%$ of the Duwamish River estuary is armored-28\% above the Turning Basin and $86 \%$ below. Riprap is the most common form of armoring, covering 39\% of the total shoreline. Reflecting the concentration of industry in the lower estuary, the Duwamish is intensively armored near its mouth: bulkhead and riprap cover $100 \%$ of the shoreline for the first river kilometer. The first major patches of shoreline vegetation appear near $\mathrm{rkm} 2$ with a restored intertidal salt marsh (Herring's House Park) and nearby Kellogg Island. With a few minor exceptions, the shoreline is overwhelmingly armored ( $>87 \%$ ) between $\mathrm{rkm} 3-7$ (Fig. 3). This pattern begins to change near rkm 8 due to a number of intertidal restoration projects in and around the Turning Basin and a transition to commercial and residential land use.

\section{Habitat Characterization}

Beach transect and aerial photo analyses confirmed that while armored and unarmored paired study sites differed in the habitat characteristics for which they were selected (i.e., proportion of armoring and vegetative cover), the two shoreline types were not completely mutually exclusive (Table 1). It was not always possible to find study sites in the lower estuary completely free of armoring and in the upper estuary some riparian vegetation was typically present even along armored shorelines. The proportion of the upper intertidal zone occupied by riprap at armored sites ranged from $40-100 \%($ mean $=72 \%)$ versus $0-39 \%($ mean $=7 \%)$ at unarmored sites. Bank gradient at armored sites (mean= $49 \%$ ) was also steeper than at unarmored sites $(21 \%)$. Within the 10-m zone adjacent to the shoreline, vegetation coverage at unarmored sites averaged $95 \%$ versus $46 \%$ at armored and tree cover, $76 \%$ versus $12 \%$.

Across all study reaches, mean maximum daily intertidal temperature was from $1.7^{\circ} \mathrm{C}$ to $2.4^{\circ} \mathrm{C}$ warmer at armored than at unarmored sites from late spring through summer (Fig. 4; two-tailed paired $t$ test, $P<0.05, n=7$ ). When examined over individual study reaches from May-July, maximum daily water temperature was higher at armored sites than at unarmored in the upper estuary, cooler in the lower estuary, and these differences positively correlated with $\mathrm{rkm}\left(R^{2}=0.58, P=0.046, n=7\right)$ (Fig. 5a). Substrate temperature was higher at armored sites at every study reach and was not correlated with river kilometer $(P=0.19, n=7)$ (Fig. 5b).

\section{Biological Sampling}

Neuston taxa richness was higher at unarmored (mean $=13.1 \pm$ $2.2 \mathrm{SE})$ than at armored $(9.0 \pm 2.8)$ sites $(P=0.040$, paired twotailed $t$ test, $n=8$ ), but abundance was not (armored $=35 \pm 13$ individuals per $10-\mathrm{m}$ tow, unarmored $=56 \pm 13)(P=0.133)$. We did not observe major differences in assemblage structure (one-way randomized block PERMANOVA, $P=0.124$ ). Across all study sites, we identified 37 unique taxa from neuston samples - nine of which were present only at unarmored sites and three only at armored. Midges (Chironomidae) were the most abundant taxa at armored sites and water mites (Acarina) numerically dominant at unarmored sites, although both were well represented at all sites-as were aphids (Aphididae) and thrips (Thysanoptera). These four groups typically represented $50-75 \%$ of individuals captured from neuston tows at all sites (Table 2). We did not observe a relationship between pair-wise differences in neuston metrics and reach location or vegetative cover $(P>0.05, n=8)$.

Epibenthic invertebrate density was on average more than an order of magnitude greater at unarmored sites (Fig. 6) and taxa richness double that at armored sites $(P<$ 0.01 , two-tailed paired $t$ test, $n=8)$. Of the 38 unique taxa
Table 1 Reach location and habitat characteristics at unarmored (U) and armored (A) study sites

River $\mathrm{Km}$ is the distance as the estuary flows from study reach to the SW corner of Harbor Island at the mouth of the Duwamish

\begin{tabular}{|c|c|c|c|c|c|c|c|c|c|c|c|}
\hline \multicolumn{4}{|c|}{ Location } & \multicolumn{4}{|c|}{ Intertidal } & \multicolumn{4}{|c|}{ Riparian } \\
\hline \multirow[t]{2}{*}{ Reach } & \multirow[t]{2}{*}{ River Km } & \multicolumn{2}{|c|}{ Site length (m) } & \multicolumn{2}{|c|}{ Bank slope (\%) } & \multicolumn{2}{|c|}{ Bank armor $(\%)$} & \multicolumn{2}{|c|}{ Veg. cover $(\%)$} & \multicolumn{2}{|c|}{ Tree cover $(\%)$} \\
\hline & & $\mathrm{U}$ & A & $\mathrm{U}$ & A & $\mathrm{U}$ & A & $\mathrm{U}$ & A & $\mathrm{U}$ & A \\
\hline 1 & 1.9 & 190 & 253 & 12 & 30 & 3 & 100 & 82 & 52 & 65 & 13 \\
\hline 2 & 2.1 & 94 & 295 & 10 & 47 & 15 & 90 & 84 & 21 & 47 & 11 \\
\hline 3 & 2.3 & 188 & 1028 & 19 & 37 & 0 & 100 & 96 & 21 & 96 & 5 \\
\hline 4 & 7.2 & 80 & 1431 & 16 & 38 & 39 & 58 & 100 & 20 & 100 & 5 \\
\hline 5 & 8.0 & 1460 & 321 & 16 & 27 & 0 & 45 & 100 & 71 & 26 & 0 \\
\hline 6 & 9.7 & 291 & 412 & 20 & 62 & 0 & 91 & 95 & 56 & 95 & 0 \\
\hline 7 & 12.9 & 972 & 72 & 49 & 71 & 0 & 55 & 100 & 90 & 81 & 60 \\
\hline 8 & 14.3 & 243 & 185 & 25 & 83 & 0 & 40 & 100 & 40 & 100 & 0 \\
\hline
\end{tabular}




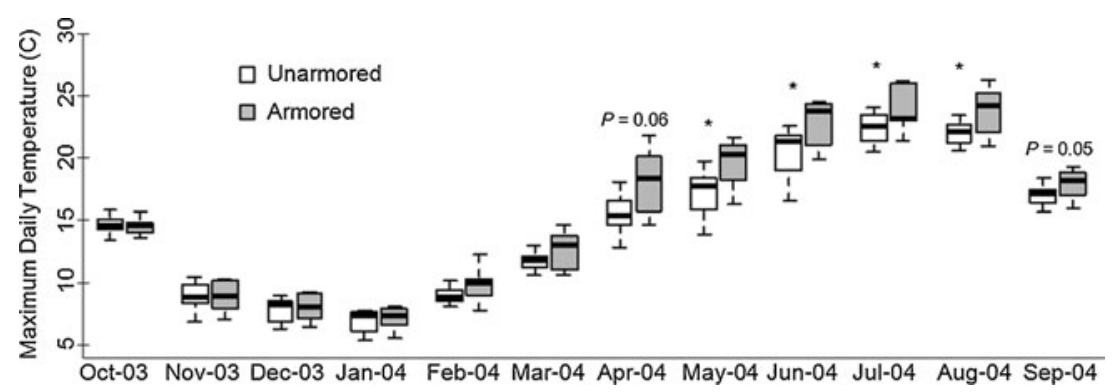

Fig. 4 Box plots of mean maximum daily intertidal temperature by month for unarmored and armored study sites from Oct 2003 to Sep 2004. Dark bands show sample median; boxes represent inter-quartile

identified across all study sites, 14 were found only at unarmored sites and five only at armored. Significant differences existed in epibenthic assemblage structure between armored and unarmored sites (one-way randomized block PERMANOVA, $P=0.023)$. SIMPER identified harpacticoid copepods as contributing the most to this dissimilarity (29.3\%) followed by oligochaete worms (12.2\%), the protists Foraminifera (11.1\%), and ostrocods (9.6\%) - all of which were more abundant at unarmored sites (Table 2). Water mites were more common at armored sites. Pair-wise

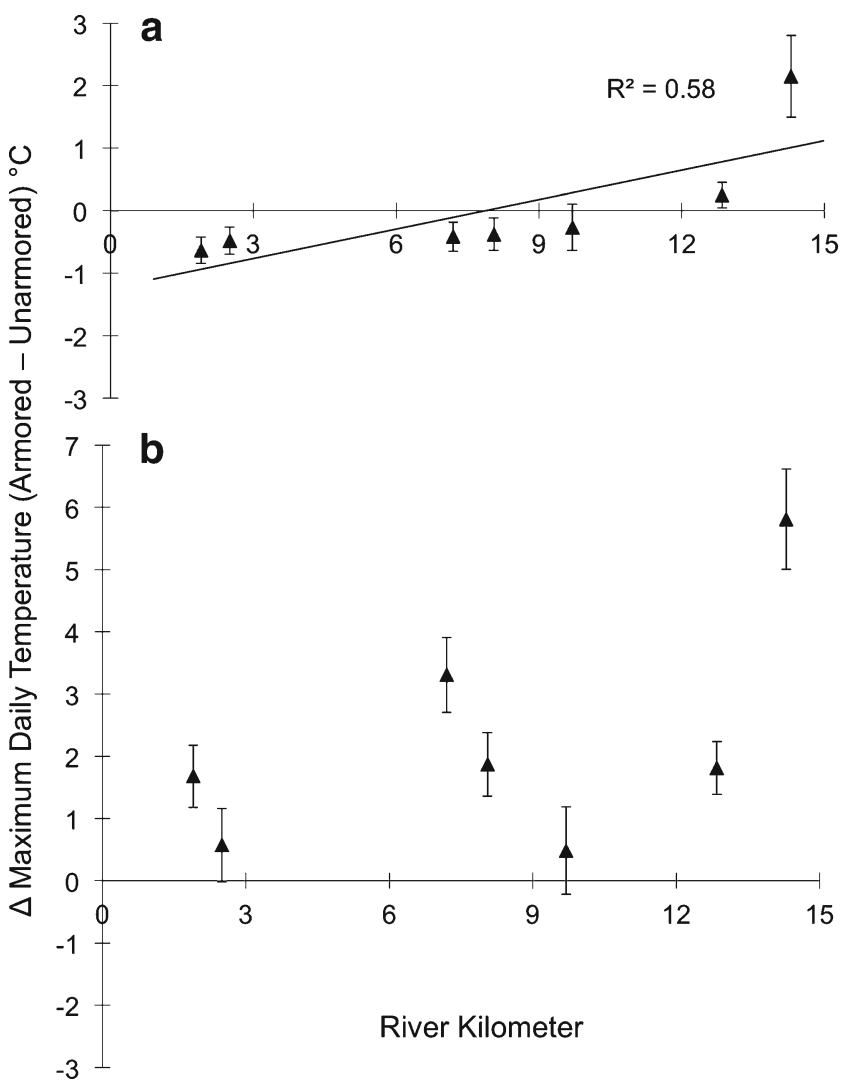

Fig. 5 Differences between paired sites (filled triangle $=$ armoredunarmored) in maximum daily temperature May-July 2004, plotted as means and $95 \%$ confidence intervals by study reach location for a water and $\mathbf{b}$ substrate range, and whiskers extend to sample minimum and maximum. Asterisks indicate that $P<0.05$ for two-tailed paired $t$ test between unarmored and armored sites $(n=7)$

differences in epibenthic density and taxa richness were both inversely correlated with $\mathrm{rkm}\left(R^{2}>0.75, P<0.01, n=8\right)$ and density differences positively correlated with extent of bank armoring $\left(R^{2}=0.59, P=0.026, n=8\right)$. We did not observe relationships between epibenthic metrics and differences in either bank slope or temperature.

We encountered only 12 fish species across the ten sites at which we collected beach seines during late-spring sampling (Table 3). Mean abundance per seine was 25.9 fish $(\mathrm{SE}=10.4)$ at unarmored sites and $4.2(\mathrm{SE}=2.3)$ at armored. Starry flounder (Platichthys stellatus), Pacific staghorn sculpin (Leptocottus armatus), and marked hatchery Chinook juveniles were the most numerically abundant species across all sites. Chinook were also caught at the greatest number of sites. Pile perch (Rhacochilus vacca) and striped perch (Embiotoca lateralis) were caught only at armored sites, as was the lone hatchery steelhead (Oncorhynchus mykiss). All other species were observed at both shoreline types - although benthic species such as starry flounder and staghorn sculpin were captured more frequently and in far higher numbers at unarmored sites (Table 3). Of the salmonids, marked fish were numerically dominant $-89 \%$ of all Chinook, $27 \%$ of coho, and $100 \%$ of steelhead. It is likely that hatchery Chinook and coho comprised an even higher proportion of our catch as not all hatchery fish are tagged or fin-clipped (Ruggerone et al. 2006). Based on the relatively low number of unmarked Chinook captured and the diet overlap reported by Cordell et al. (2011), we combined marked and unmarked Chinook for the purpose of diet analyses.

Terrestrial insects dominated the diet of Chinook salmon (forklengths 58-91 mm) captured from armored and unarmored sites numerically, by weight, and in frequency of occurrence-contributing over $80 \%$ of total IRI (Table 2). The aquatic immature life stages of benthic insects contributed another $10-30 \%$ of Chinook diet by relative abundance (Fig. 7). Due to partial digestion, many insects could not be classified beyond the class Insecta. Of those specimens still relatively intact, taxa which consistently contributed the most to total IRI were the terrestrial adult Chironomidae, Aphidae, and Tethinidae; benthic immature Chironomidae; 
Table 2 Invertebrate taxa identified in neuston, epibenthic, and fish diet samples
Taxonomic resolution varied by sample type, but results are reported here as order-level or higher. Data for neuston and epibenthos represent the percent contribution of each taxa to total abundance across all 16 study sites. Diet data are reported as the percent contribution of each taxa to the index of relative abundance (IRI) by fish species and site type - unarmored (U) and armored (A). Sample size (n) refers to sites sampled for neuston and epibenthos, and individuals for fish diet. IRI is reported here as means across all fish collected by species and site type, but statistical analyses were restricted to study reaches where a given species was present at both paired sites

\begin{tabular}{|c|c|c|c|c|c|c|c|c|}
\hline & \multirow{2}{*}{\multicolumn{2}{|c|}{$\frac{\text { Neuston }}{\% \text { of total }}$}} & \multirow{2}{*}{\multicolumn{2}{|c|}{$\frac{\text { Epibenthos }}{\% \text { of total }}$}} & \multicolumn{4}{|c|}{ Fish diet (IRI) } \\
\hline & & & & & \multicolumn{2}{|c|}{ Chinook } & \multicolumn{2}{|c|}{ Chum } \\
\hline & $\begin{array}{l}\mathrm{U} \\
(8)\end{array}$ & $\begin{array}{l}\text { A } \\
(8)\end{array}$ & $\begin{array}{l}U \\
(8)\end{array}$ & $\begin{array}{l}\text { A } \\
(8)\end{array}$ & $\begin{array}{l}\mathrm{U} \\
(43)\end{array}$ & $\begin{array}{l}\text { A } \\
(30)\end{array}$ & $\begin{array}{l}\text { U } \\
\text { (33) }\end{array}$ & $\begin{array}{l}\text { A } \\
\text { (11) }\end{array}$ \\
\hline \multicolumn{9}{|l|}{ Terrestrial arthropods } \\
\hline Insecta & 1.9 & 0.7 & & & 49.3 & 58.3 & 15.6 & 24.0 \\
\hline Coleoptera & 2.2 & 1.3 & & & 0.1 & $<0.1$ & & \\
\hline Diptera & 13.5 & 11.6 & & & 24.4 & 17.7 & 1.4 & 24.3 \\
\hline Ephemeroptera & 0.1 & & & & & & & \\
\hline Hemiptera & 11.5 & 4.9 & & & 9.1 & 3.7 & 0.8 & 31.1 \\
\hline Hymenoptera & 5.5 & 5.1 & & & 0.5 & 1.2 & & 0.2 \\
\hline Lepidoptera & 0.4 & 0.5 & & & $<0.1$ & $<0.1$ & & \\
\hline Pscoptera & 2.3 & 0.9 & & & 0.2 & & & \\
\hline Thysanoptera & 4.1 & 4.0 & & & & & $<0.1$ & \\
\hline Polyxenidae & 0.1 & & & & & & & \\
\hline \multicolumn{9}{|l|}{ Semi-aquatic arthropods } \\
\hline Arachnida & 16.5 & 5.6 & 0.8 & 1.3 & 0.3 & 0.5 & $<0.1$ & 0.2 \\
\hline Collembola & 4.4 & 2.4 & & & $<0.1$ & $<0.1$ & & 0.9 \\
\hline \multicolumn{9}{|l|}{ Benthic crustaceans } \\
\hline Amphipoda & & & 2.1 & 0.4 & 4.9 & 12.6 & 1.3 & 1.5 \\
\hline Cirripedia & & & & & 0.7 & $<0.1$ & 0.3 & \\
\hline Cumacea & & & 0.1 & & $<0.1$ & & & \\
\hline Harpacticoida & & & 52.3 & 6.0 & & $<0.1$ & 72.9 & 7.7 \\
\hline Isopoda & & & 0.2 & 0.1 & & & & \\
\hline Mysida & & & & & & & 1.1 & \\
\hline Ostrocoda & & & 4.3 & 0.3 & & & & \\
\hline Tanaidacea & & & 1.9 & & & & & \\
\hline \multicolumn{9}{|l|}{ Benthic insects } \\
\hline Coleoptera (immature) & & & & 0.1 & $<0.1$ & $<0.1$ & & \\
\hline Diptera (immature) & & & 1.8 & 1.4 & 8.3 & 3.9 & 6.2 & 9.0 \\
\hline Hemiptera (immature) & & & & 0.1 & & & & \\
\hline Plecoptera (immature) & & & 0.1 & & & & & \\
\hline \multicolumn{9}{|l|}{ Benthic worms } \\
\hline Nematoda & & & 5.3 & 0.5 & & & & \\
\hline Oligochaeta & & & 7.9 & 0.5 & & & & \\
\hline Polychaeta & & & 0.5 & & 1.6 & & 0.4 & \\
\hline \multicolumn{9}{|l|}{ Benthic miscellaneous } \\
\hline Foraminifera & & & 11.4 & 0.1 & & & & \\
\hline Tardigrada & & & & 0.4 & & & & \\
\hline \multicolumn{9}{|l|}{ Planktonic crustaceans } \\
\hline Cyclopoida & & & 0.1 & 0.1 & $<0.1$ & & $<0.1$ & 0.3 \\
\hline Decapoda (immature) & & & & & 0.2 & 1.4 & & \\
\hline
\end{tabular}

and the amphipod genus Americorophium. In total, 34 unique prey items were identified across all Chinook stomach-content samples. We did not detect differences in the diet of Chinook captured from armored versus unarmored sites based on assemblage structure (one-way PERMANOVA, $P>0.05$ ).
Diet composition of chum (forklengths 35-66 mm) differed both by number and weight between armored and unarmored sites (one-way PERMANOVA, $P<0.05$ ) (Fig. 7). On a numeric basis, harpacticoid copepods contributed the greatest $(19.4 \%)$ to dissimilarities between groups and represented a higher proportion of the diet of chum 


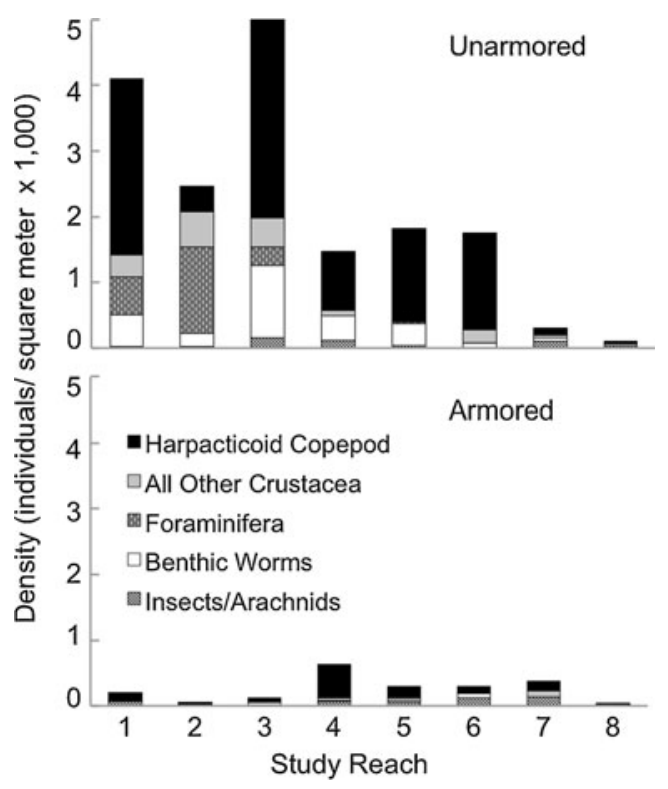

Fig. 6 Epibenthic density by major taxonomic groups for unarmored and armored study sites

collected at unarmored sites, as did immature chironomids $(10 \%)$. Aphids, adult chironomids, and other terrestrial insects comprised a higher proportion of diet at armored sites and contributed another $10-15 \%$ each to average dissimilarity. Harpacticoid copepods also contributed the greatest to differences between groups in terms of relative abundance by weight. Across all study sites, a total of 19 unique chum prey items were observed. Of those specimens identifiable beyond the class level, taxa which contributed the most to IRI at armored sites were Aphids (30\%), adult Chironomids (24\%), and immature Chironomids (9\%) (Table 2). At unarmored sites, harpacticoid copepods contributed $73 \%$ to the IRI, followed by immature Chironomid (6\%), and adult Chironomid (1\%).

\section{Discussion}

The extensive armoring and lack of riparian vegetation that characterize the Duwamish estuary has severed connections between terrestrial and aquatic habitats. Over two thirds of the total shoreline is armored and in the lower estuary riparian vegetation present along only $11 \%$ of the shoreline- much of this dominated by non-native species. While the Duwamish estuary is at one end of the urban gradient in the Pacific Northwest, it reflects a global trend. Of the world's 19 megacities (population $>10$ million), 15 are located on estuaries (UN 2008). In most of these cities, shorelines have long been extensively modified - but armoring is still accelerating in industrializing parts of the world (De Vriend et al. 2011). Among a host of other deleterious effects [reduced intertidal habitat, truncated delivery of upland sediment and organic material, and decreased tidal deposition of fine sediment and beach wrack (Romanuk and Levings 2005; Dugan et al. 2008; Sobocinski et al. 2010)] — loss of shading from vegetation removal and lower moisture retention on armored surfaces may also alter temperature regime (Rice 2006).

Temperature is one fundamental component of habitat quality that exerts a wide array of direct and indirect biological effects on intertidal organisms (Southward 1958). We observed higher water temperatures at armored sites furthest upstream, where tidal influence was minimal. At lower estuary reaches, mean daily water temperature at armored sites was actually slightly cooler - potentially due to less warming
Table 3 Fish species captured across five sampled study reaches with mean length $\pm 1 \mathrm{SE}$

Species are ordered from most to least abundant and reported as percent of total catch across all sites and occurrence rate at unarmored (U) and armored (A) sites. Length is recorded in $\mathrm{mm}$ and refers to forklength for salmonids and standard length for all other fish

\begin{tabular}{|c|c|c|c|c|c|c|}
\hline \multirow[t]{2}{*}{ Common name } & \multirow[t]{2}{*}{ Scientific name } & \multirow[t]{2}{*}{ Length } & \multicolumn{2}{|c|}{$\%$ of total } & \multicolumn{2}{|c|}{ Occurrence $(\%)$} \\
\hline & & & $\mathrm{U}$ & A & $\mathrm{U}$ & A \\
\hline Starry flounder & Platichthys stellatus & $31( \pm 0.9)$ & 30.8 & 0.2 & 100 & 40 \\
\hline Pacific staghorn sculpin & Leptocottus armatus & $33( \pm 0.6)$ & 23.5 & 0.7 & 100 & 40 \\
\hline Chinook (hatchery) & Oncorhynchus tshawytscha & $81( \pm 0.7)$ & 6.9 & 8.9 & 100 & 80 \\
\hline Chum & Oncorhynchus keta & $48( \pm 0.6)$ & 11.4 & 1.4 & 80 & 60 \\
\hline Shiner perch & Cymatogaster aggregata & $91( \pm 1.3)$ & 1.2 & 0.7 & 40 & 80 \\
\hline Chinook (unmarked) & Oncorhynchus tshawytscha & $83( \pm 0.4)$ & 0.7 & 0.3 & 100 & 60 \\
\hline Three-spine stickleback & Gasterosteus aculeatus & $43( \pm 3.1)$ & 0.4 & 0.1 & 80 & 20 \\
\hline Northern anchovy & Engraulis mordax & $35( \pm 2.1)$ & 0.3 & 0.3 & 40 & 20 \\
\hline Coho (unmarked) & Oncorhynchus kisutch & $114( \pm 2.4)$ & 0.1 & 0.1 & 20 & 20 \\
\hline Coho (hatchery) & Oncorhynchus kisutch & $123( \pm 3.1)$ & 0.1 & 0.1 & 20 & 20 \\
\hline Snake prickleback & Lumpenus sagitta & $150(\mathrm{NA})$ & 0.1 & 0.1 & 20 & 20 \\
\hline Striped perch & Embiotoca lateralis & $108( \pm 1.7)$ & & 0.4 & & 20 \\
\hline Pile perch & Rhacochilus vacca & $239( \pm 9.0)$ & & 0.2 & & 20 \\
\hline Steelhead (hatchery) & Oncorhynchus mykiss & 150 (NA) & & 0.1 & & 20 \\
\hline
\end{tabular}


Fig. 7 Mean relative abundance $( \pm 1 \mathrm{SE})$ of major prey categories for juvenile Chinook salmon plotted by $\mathbf{a}$ number and $\mathbf{b}$ weight from armored $(n=30)$ and unarmored $(n=36)$ study sites, and for chum salmon by $\mathbf{c}$ number and $\mathbf{d}$ weight from armored $(n=11)$ and unarmored $(n=21)$ study sites. Data are plotted for individuals captured from study reaches where species were present at both paired sites

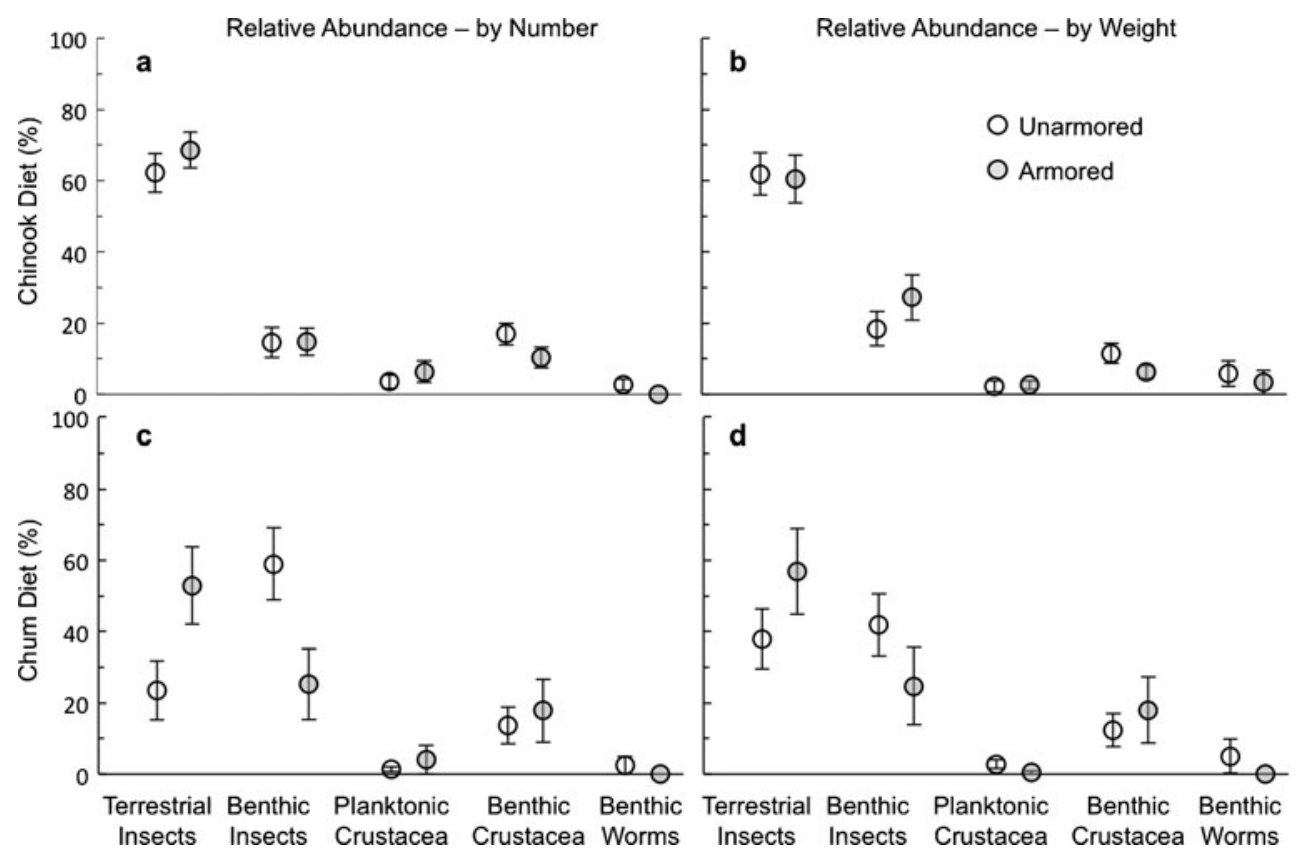

of shallow-water habitats. While we did not observe consistent differences by shoreline type, water temperature at all study sites frequently exceeded $20^{\circ} \mathrm{C}$ from May to July. Similar Duwamish water temperatures are reported in Ruggerone et al. (2006) and are approaching reported thermal tolerances for salmonids (Richter and Kolmes 2005). Where we did see consistently warmer temperatures at armored sites was in exposed substrate at low tide. While elevated substrate temperatures at armored shorelines may not be problematic for adult fish - aquatic vegetation and less-mobile organisms or life stages are vulnerable to temperature-mediated stress (Rice 2006; Jackson et al. 2008).

Along with potential indirect effects via microclimate, shoreline armoring affects aquatic and riparian species directly via changes in physical habitat (Bilkovic and Roggero 2008; Jackson et al. 2008). Shoreline hardening from riprap or bulkhead placement limits burrowing habitat for benthic species, and steeper banks constrain development of submerged aquatic vegetation and the food and protection they confer to aquatic species (Lubbers et al. 1990; Peterson et al. 2000). Armored shorelines of the Duwamish contained only a fraction of the epibenthic assemblage observed at nearby unarmored siteswith dissimilarity between paired sites increasing the greater the difference in armoring. Taxonomic dissimilarity between paired sites was also greater at downstream reaches where overall epibenthic density was highest-likely reflecting the salinity gradient across our study reaches. In contrast, we did not detect large differences in neustonic invertebrates by shoreline type - potentially because neuston nets capture not only invertebrates that may have recently fallen into a site from the adjoining shoreline, but also those that are delivered by the prevailing current. Sampling techniques such as fall-out traps that target direct terrestrial invertebrate input would likely have been a better approach for shoreline comparisons (see Gray et al. 2002).

Although a handful of international studies have examined fish use associated with armored estuarine shorelines (see Bulleri and Chapman (2010) and Shipman et al. (2010) for recent reviews), many questions remain. Part of the challenge lays in finding sampling methods equally effective across different shoreline types, a difficulty we also encountered in this study. Using enclosure nets and snorkel surveys along City of Seattle marine shorelines, Toft et al. (2007) found fewer flatfish associated with intertidal riprap, and higher groupings of pelagic fish where riprap extended into the subtidal and steepened the shoreline. We observed a similar pattern in the Duwamish, with more pelagic species at armored sites and far fewer flat fish (Table 3). An estuarywide survey of juvenile Chinook using a variety of seine sampling across the Duwamish found no differences in habitat utilization by bank armoring or restoration status (Ruggerone et al. 2006), while a companion study employing enclosure net sampling detected higher densities of juvenile Chinook in restored versus armored shorelines in one of three pairings (Cordell et al. 2011). Identifying differences in fish assemblages associated with shoreline armoring is the first step-examining the mechanisms behind these differences still needs refinement.

We found that chum salmon captured from unarmored sites contained more benthic prey sources than from armored. Although we cannot be certain that prey were consumed at the specific site at which a given fish was captured, this finding agrees with the large difference in epibenthic invertebrate density between armored and unarmored sites. One 
potential reason that we did not observe differences in Chinook diet is that these larger-bodied fish are likely moving around more and may be feeding further offshore. Another complicating factor is surface-feeding conditioning of hatchery juveniles, which comprise the majority of Duwamish Chinook (Reinhardt 2001; Ruggerone et al. 2006). Regardless of hatchery origin, terrestrial food sources typically comprise a large component of the diet of juvenile salmonids in estuarine habitats (Gray et al. 2002; Romanuk and Levings 2005). Terrestrial invertebrates accounted for $>40 \%$ of diet content in both chum and Chinook juveniles in the Duwamishunderscoring the importance of shoreline vegetation. Our diet results are based on a relatively small number of fish sampled over a limited time frame, and expanded study is warranted. Use of enclosure net sampling would also help reduce uncertainty on location of prey acquisition (Toft et al. 2007; Cordell et al. 2011).

That estuarine shoreline armoring is globally widespread and severe in urban areas is well established (Airoldi et al. 2005). With continued human population growth, migration into cities, and climate change - the problem is set to worsen (Dugan et al. 2008). Although a growing body of literature has emerged over the last decade, study of the ecological effects of shoreline armoring still lags far behind inventories of chemical or physical habitat degradation (Bulleri and Chapman 2010). Research is particularly needed from parts of the world where estuarine cities are growing most rapidly (UN 2008). We cannot return already industrialized estuaries to pre-development conditions, but can help limit or at least improve the design of future shoreline development - and where opportunities present themselves, better direct restoration efforts. Preserving or attempting to restore patches of natural habitat in urban landscapes rarely is the most cost-effective approach to species conservation (Simenstad et al. 2005), but does present unparalleled opportunity to engage the populace in natural resource management. Ultimately, it is a shift in societal values along with further scientific study that is needed to better protect the world's estuaries.

Acknowledgments We thank Judith Noble and Julie Hall from Seattle Public Utilities for sharing their insider knowledge of the Duwamish estuary. We are grateful for field and data entry assistance from Jesse Ayers, Todd Bennett, Alicia Godersky, Kris Kloehn, Bill Mowitt, Andrea Pratt, Frank Sommers, and other members of the Watershed Program. Invertebrate samples were processed by Katie Dodd and Ben Starkhouse, with taxonomic expertise provided by Jeff Cordell at the University of Washington. Hiroo Imaki and Martin Liermann provided consultation in GIS and statistics, and Casey Rice and Correigh Greene contributed valuable comments on earlier drafts of this manuscript. This research would not have been possible without funding from the Northwest Fisheries Science Center Internal Grant Program.

Open Access This article is distributed under the terms of the Creative Commons Attribution License which permits any use, distribution, and reproduction in any medium, provided the original author(s) and the source are credited.

\section{References}

Airoldi, L., M. Abbiati, M.W. Beck, S.J. Hawkins, P.R. Jonsson, D. Martin, P.S. Moschella, A. Sundelof, R.C. Thompson, and P. Aberg. 2005. An ecological perspective on the development and design of low-crested and other hard coastal defense structures. Coastal Engineering 52: 1073-1087.

Anderson, M.J., R.N. Gorley, and K.R. Clarke. 2008. PERMANOVA+for PRIMER: guide to software and statistical methods. Plymouth, UK: PRIMER-E.

Bilkovic, D.M., and M.M. Roggero. 2008. Effects of coastal development on nearshore estuarine nekton communities. Marine Ecology Progress Series 358: 27-39.

Blomberg, G., C. Simenstad, and P. Hickey. 1988. Changes in Duwamish River estuary habitat over the past 125 years. In Proceedings of the First Annual Meeting on Puget Sound Research, ed. K. Fletcher, 437-454. Seattle, Washington: Puget Sound Water Quality Authority.

Bulleri, F., and M.G. Chapman. 2010. The introduction of coastal infrastructure as a driver of change in marine environments. Journal of Applied Ecology 47: 26-35.

Clarke, K.R., and R.N. Gorley. 2006. Primer v6: user manual/tutorial. Plymouth, UK: PRIMER-E.

Cordell, J.R., J.D. Toft, A. Gray, G.T. Ruggerone, and M. Cooksey. 2011. Functions of restored wetlands for juvenile salmon in an industrialized estuary. Ecological Engineering 37: 343-353.

De Vriend, H.J., Z.B. Wang, T. Ysebaert, P.M.J. Herman, and P. Ding. 2011. Eco-morphological problems in the Yangtze estuary and the Western Schedlt. Wetlands 31: 1033-1042.

Dugan, J.E., D.M. Hubbard, I.F. Rodil, D.L. Revell, and S. Schroeter. 2008. Ecological effects of coastal armoring on sandy beaches. Marine Ecology 29: 160-170.

Gray, A., C.A. Simenstad, D.L. Bottom, and T.J. Cornwell. 2002. Contrasting functional performance of juvenile salmon habitat in recovering wetlands of the Salmon River estuary, Oregon, U.S.A. Restoration Ecology 10: 514-526.

Jackson, N.L., D.R. Smith, and K.F. Nordstrom. 2008. Physical and chemical changes in the foreshore of an estuarine beach: implications for viability and development of horseshoe crab (Limulus polyphemus) eggs. Marine Ecology Progress Series 355: 209-218.

Lotze, H.K., H.S. Lenihan, B.J. Bourque, R.H. Bradbury, R.G. Cooke, M.C. Kay, S.M. Kidwell, M.X. Kirby, C.H. Peterson, and J.B.C. Jackson. 2006. Depletion, degradation, and recovery potential of estuaries and coastal seas. Science 312: 1806-1809.

Lubbers, L., W.R. Boynton, and W.M. Kemp. 1990. Variations in structure of estuarine fish communities in relation to abundance of submerged vascular plants. Marine Ecology Progress Series 65: $1-14$.

National Research Council (NRC). 2006. Mitigating shore erosion along sheltered coasts. Washington, DC: National Academies Press.

Peterson, M.S., and M.R. Lowe. 2009. Implications of cumulative impacts to estuarine and marine habitat quality for fish and invertebrate resources. Reviews in Fisheries Science 17: 505-523.

Peterson, M.S., B.H. Comyns, J.R. Hendon, P.J. Bond, and G.A. Duff. 2000. Habitat use by the early life-history stages of fishes and crustaceans along a changing estuarine landscape: differences between natural and altered shoreline sites. Wetlands Ecology and Management 8: 209-219. 
Pinkas, L., M.S. Oliphant, and I.L.K. Iverson. 1971. Food habits of albacore, bluefin tuna, and bonito in California water. California Fish and Game Bulletin 152: 1-105.

Reinhardt, U.G. 2001. Selection for surface feeding in farmed and searanched masu salmon juveniles. Transactions of the American Fisheries Society 130: 155-158.

Rice, C.A. 2006. Effects of shoreline modification on a Northern Puget Sound beach: microclimate and embryo mortality in surf smelt. Estuaries and Coasts 29: 63-71.

Richter, A., and S.A. Kolmes. 2005. Maximum temperature limits for Chinook, coho, and chum salmon, and steelhead trout in the Pacific Northwest. Reviews in Fisheries Science 13: 23-49.

Romanuk, T.N., and C.D. Levings. 2003. Associations between arthropods and supralittoral ecotone: dependence of aquatic and terrestrial taxa on riparian vegetation. Environmental Entomology 32: $1343-1353$.

Romanuk, T.N., and C.D. Levings. 2005. Stable isotope analysis of trophic position and terrestrial vs. marine carbon sources for juvenile Pacific salmonids in nearshore marine habitats. Fisheries Management and Ecology 12: 113-121.

Rozas, L.P., and T.J. Minello. 1997. Estimating densities of small fishes and decapods crustaceans in shallow estuarine habitats: a review of sampling design with focus on gear selection. Estuaries 20: 199-213

Ruggerone, G.T., T.S. Nelson, J. Hall, and E. Jeanes. 2006. Habitat utilization, migration timing, growth, and diet of juvenile Chinook salmon in the Duwamish River and Estuary. Renton, Washington: King Conservation District.

Ruiz, G.M., A.H. Hines, and M.H. Posey. 1993. Shallow water as a refuge habitat for fish and crustaceans in non-vegetated estuaries: an example from Chesapeake Bay. Marine Ecology Progress Series 99: 1-16.
Shipman, H., M.N. Dethier, G. Gelfenbaum, K.L. Fresh, and R.S. Dinicola. 2010. Puget Sound shorelines and the impacts of armoring. Reston, Virginia: U.S. Geological Survey.

Simenstad, C., C. Tanner, C. Crandell, J. White, and J. Cordell. 2005. Challenges of habitat restoration in a heavily urbanized estuary: evaluating the investment. Journal of Coastal Research 40: 6-23.

Simenstad, C.A., M. Ramirez, J. Burke, M. Logsdon, H. Shipman, C. Tanner, J. Toft, B. Craig, C. Davis, J. Fung, P. Bloch, K. Fresh, D. Myers, E. Iverson, A. Bailey, P. Schlenger, C. Kiblinger, P. Myre, W. Gerstel, and A. MacLennan. 2011. Historical change of Puget Sound shorelines: Puget Sound nearshore ecosystem project change analysis. Puget Sound Nearshore Report No. 2011-01. Olympia, Washington: Washington Department of Fish and Wildlife.

Sobocinski, K.L., J.R. Cordell, and C.A. Simenstad. 2010. Effects of shoreline modifications on supratidal macroinvertebrate fauna on Puget Sound, Washington beaches. Estuaries and Coasts 33: 699-711.

Southward, A.J. 1958. Note on the temperature tolerances of some intertidal animals in relation to environmental temperatures and geographical distribution. Journal of the Marine Biological Association of the United Kingdom 37: 49-66.

Toft, J.D., J.R. Cordell, C.A. Simenstad, and L.A. Stamatiou. 2007. Fish distribution, abundance, and behavior along city shoreline types in Puget Sound. North American Journal of Fisheries Management 27: 465-480.

United Nations (UN). 2008. World urbanization prospects: the 2007 revision. New York: Department of Economics and Social Affairs Population Division.

United Nations Population Fund (UNPF). 2007. State of world population 2007: unleashing the potential of urban growth. New York: United National Population Fund. 